Revista da Universidade Estadual de Alagoas/UNEAL

e-ISSN 2318-454X, Ano 12, Vol. 12 (3), julho/outubro (2020).

\title{
Biometrics of fruits and seeds sold in open markets
}

\section{Biometria de frutos e sementes comercializados em feiras livres}

\author{
Maria José Ferreira da CONCEIÇÃO ${ }^{1}$, Rubens Pessoa de BARROS ${ }^{2}$. \\ ${ }^{1}$ Universidade Estadual de Alagoas, graduação em ciências biológicas; \\ ${ }^{2}$ Professor do Departamento de Ciências Biológicas da Universidade Estadual de Alagoas/Campus I.; \\ E-mail: pessoa.rubens@gmail.com.
}

* E-mail do autor principal: mariamjfcx@gmail.com.

Recebido em junho de 2020 e aceito em setembro de 2020.

Resumo - O Brasil encontra-se entre os três maiores produtores mundiais de frutas, estando no terceiro lugar no ranking mundial de produção. O país possui elevado consumo interno, e ainda exporta uma quantidade razoável, e desta forma a economia é influenciada diretamente pela fruticultura. Para dar suporte a estes estudos são necessários dados fornecidos pela biometria. Partindo dessa premissa, este estudo teve como objetivo analisar os dados da biometria de frutos comercializados em feiras livres do Agreste Alagoano, Nordeste do Brasil, para auxiliar como parâmetro na aquisição da compra. O delineamento experimental planejado foi o inteiramente casualizado, onde o pesquisador escolheu aleatoriamente as bancas de feiras e a coleta dos frutos. Foram entrevistados com o consentimento livre cerca de duzentos usuários das feiras livres. Os tratamentos se constituíram na coleta de dez espécies de frutos e as repetições cinco feiras semanais no período de outubro de 2019 a fevereiro de 2020. Os frutos foram estudados em triplicatas, utilizando-se uma amostra de dez unidades de cada espécie em cada feira visitada. Cada feira coletou-se três frutos das dez espécies comercializadas. As espécies de frutos foram: abacate, goiaba, laranja, limão, maçã, manga, mamão, maracujá, melão e pera. Os dados dos entrevistados revelam que o tamanho da fruta foi a característica mais significativa para a decisão da compra da fruta comercializada. Os resultados revelam que o maracujá é a fruta cujo sabor tem destaque em meio à clientela. As diferenças significativas na biometria das espécies de frutos desse estudo contribuem na decisão da compra. A pesquisa concluiu que dentre as variáveis analisadas em cada espécie, as de maior influência no momento da compra dos frutos foram os tamanhos (diâmetro equatorial dos frutos e diâmetro polar) e a biomassa do fruto.

Palavras-chave: Biometria. Frutos. Feira Livre.

Abstract - Brazil is among the three largest world producers of fruit, being in the third place in the world ranking of production. The country has high domestic consumption, and still exports a reasonable amount, and in this way the economy is directly influenced by fruit production. To support these studies, data provided by biometrics is required. Based on this premise, this study aimed to analyze the data on the biometrics of fruits sold in open markets in Agreste Alagoano, Northeast of Brazil, to assist as a parameter in the purchase acquisition. The planned experimental design was 
Revista da Universidade Estadual de Alagoas/UNEAL e-ISSN 2318-454X, Ano 12, Vol. 12 (3), julho/outubro (2020).

completely randomized, where the researcher randomly chose the stalls for the fairs and the collection of fruits. About two hundred users of open markets were interviewed with free consent. The treatments consisted of the collection of ten species of fruits and the repetitions five weekly fairs from October 2019 to February 2020. The fruits were studied in triplicates, using a sample of ten units of each species in each fair visited. Each fair collected three fruits from the ten species sold. The fruit species: avocado, guava, orange, lemon, apple, mango, papaya, passion fruit, melon and pear. The interviewees' data reveal that the size of the fruit was the most significant characteristic for the decision to purchase commercialized fruit. The results reveal that passion fruit is the fruit whose flavor stands out among customers. The significant differences in the biometry of the fruit species in this study contribute to the purchase decision. The research concluded that among the variables analyzed in each species, those with the greatest influence at the time of fruit purchase were the sizes (equatorial diameter of the fruit and polar diameter) and the biomass of the fruit.

Keywords: Biometrics. Fruits. Free Market.

\section{Introdução}

A biometria é o estudo da Biologia que se utiliza de métodos da estatística para conhecer as características físicas dos seres vivos. Ela fornece dados valiosos para a conservação e exploração das espécies, ajudando no uso eficaz e sustentável (ARAÚJO et al., 2014).

A caracterização biométrica de frutos e sementes é uma ferramenta essencial para discernir espécies do mesmo gênero; ela também contribui fornecendo informações ecológicas de grupos de plantas presentes em diferentes regiões geográficas, onde o ambiente pode influenciar os fenótipos. Desta maneira, a descrição biométrica permite diferir espécies do mesmo gênero, identificar variações genéticas dentro de populações da mesma espécie, e analisar a relação dos fatores ambientais com as variações citadas (SOUZA e CAVALCANTE, 2019; ARAÚJO et al., 2014).

A Biometria é uma aliada da fruticultura, pois como citado anteriormente as informações obtidas através dela contribuem para os estudos de melhoramento genético, e desta maneira pode influenciar diretamente na qualidade dos frutos comerciais, tendo como consequência um resultado positivo para a economia, inclusive do Brasil.

O Brasil é um importante produtor de alimentos, e dentre os fatores que contribuem para esta realidade estão: território extenso, clima, diversidade de espécies, solo, água disponível para irrigação, fácil mão-de-obra, etc.; estes colaboram para que haja uma produção de aproximadamente 41,5 milhões de toneladas por ano (SILVA et al., 2013).

Segundo Rodrigues (2015), o país está em terceiro lugar na lista dos maiores produtores mundiais de frutas, sendo precedido pela China e Índia que ocupam respectivamente a primeira e segunda colocação. Utilizando cálculos feitos pela Confederação da Agricultura e Pecuária do Brasil (CNA) e pelo Instituto Brasileiro de Frutas (IBRAF), Rodrigues registrou também que em 2013 e 2014, a produção superou 43 milhões de toneladas; gerando, direta e indiretamente, emprego para 5,6 milhões de pessoas.

Além de ter o consumo interno elevado, o país exporta uma quantidade razoável, e desta forma a economia é influenciada diretamente pela fruticultura. Por estar distribuída por todo o território nacional, e ser responsável por $27 \%$ da mão de obra agrícola, também possui 
Revista da Universidade Estadual de Alagoas/UNEAL e-ISSN 2318-454X, Ano 12, Vol. 12 (3), julho/outubro (2020).

importância social, uma vez que gera renda, emprego, e ajuda a desenvolver o agronegócio (FACHINELLO et al., 2011).

Dentre os locais onde ocorre a comercialização de frutos, está a feira livre, um comércio móvel, realizado nas áreas urbanas, considerado um dos mais tradicionais meios de comercialização de alimentos a varejo (ARAUJO et al., 2015), o qual oferece facilidades para agricultores que não estão acostumados a lidar com aparatos tecnológicos avançados, pois utilizam apenas tecnologia básica, e baixo nível de conhecimento técnico; características estas que somadas ao trabalho braçal presente neste meio, ao foco na subsistência, a ausência ou precariedade de trabalhos de proteção social, e ao fato de atender as camadas sociais médias e populares, acabam por qualificar as feiras como integrantes do circuito inferior da economia de suas cidades-sede (BASTOS, 2020).

Neste contexto, dentre as pequenas cidades do interior nordestino que se utilizam da feira livre, estão às cidades do Agreste Alagoano - região que sediou a pesquisa. A feira fornece principalmente produtos agrícolas para o abastecimento da população local, mas também é muito visitada por pessoas vindas de cidades vizinhas.

Durante o ano, as frutas mais comuns que podem ser vistas nas bancas dos feirantes do agreste são: Acerola, Abacate, Abacaxi, Banana, Caju, Carambola, Coco, Goiaba, Graviola, Jaca, Jabuticaba, Jambo, Jenipapo, Laranja, Limão, Mamão, Manga, Maracujá, Melancia, Melão, Pera, Pitomba, Seriguela, Uva e Tangerina. Dentre estas foram escolhidas para esta pesquisa o abacate, a laranja, o maracujá amarelo, a goiaba, o mamão, a manga, e o melão, por serem encontradas com mais frequência nas feiras.

O abacate (Persea americana Mill.) é uma fruta pertencente à família Lauraceae, de origem americana; é rica em lipídios, proteínas, fibras, vitamina E, carotenóides, esteróis, compostos fenólicos e minerais; apresenta grande potencial econômico devido ao aproveitamento de seus componentes na indústria farmacêutica, de cosméticos e de biocombustível (NOGUEIRA-DE-ALMEIDA et al., 2018).

A goiaba (Psidium guajava L.) integra a família Myrtaceae, é uma fruta que possui origem divergente, porém ela pode ser encontrada em quase todas as regiões tropicais e subtropicais do mundo, em virtude da sua fácil adaptação a diferentes climas e sua fácil propagação por semente (MELLO FILHO, 2020). É rica em sais minerais, em vitamina C, e possui princípios ativos úteis para a medicina (PEREIRA, 2016).

A laranja (Citrus sinensis L.) faz parte da família Rutaceae, possui origem oriental, e alguns registros apontam que, provavelmente, é originária do sul asiático, mais precisamente da China (OLIVEIRA e MENELAU, 2017). É uma fruta cítrica rica em vitamina C, minerais, carboidratos, carotenóides, flavonóides, potássio e ácido fólico (FERREIRA et al. 2019).

O limão (Citrus limon L.) é uma fruta derivada de uma planta que se encontra botanicamente enquadrada na família das árvores Rutuaceae, de origem asiática. Ele é rico em vitamina $\mathrm{C}$, mas também possui as vitaminas $\mathrm{B}, \mathrm{B} 1, \mathrm{~B} 2, \mathrm{~B} 3$, PP, pró vitamina A; e minerais como: fósforo, cálcio, magnésio, manganês, sódio e ferro (OLIVEIRA JÚNIOR., 2019).

A maçã pertence à família das Rosáceas, sub-família das Pomóideas e género Malus. A Malus communis L. e Malus permiler M. são as duas espécies que deram origem a todas as variedades hoje conhecidas, das quais derivaram também alguns híbridos espontâneos. A macieira, na sua forma silvestre, é certamente originária da Ásia Central e do Caúcaso (GUINÉ, 2016). É uma fruta rica em vitaminas A, B6, B12 e D (PATTARO et al., 2020). 
Revista da Universidade Estadual de Alagoas/UNEAL e-ISSN 2318-454X, Ano 12, Vol. 12 (3), julho/outubro (2020).

O mamão (Carica papaya L.), integrante da família Caricaceae, teve sua origem no Noroeste da América do sul, vertente oriental dos Andes, exatamente na Bacia Amazônica Superior. É uma excelente fonte de energia, cálcio, fósforo, proteínas, vitaminas A e C, e ainda possui propriedades digestivas e medicinais (EMBRAPA, 2013).

A manga (Mangifera indica L.) pertence à família Anacardiaceae, seu centro de origem é a Índia (COELHO et al.,2014). É uma fruta rica em vitaminas A, C, E, flavonoides e outros nutrientes que conferem propriedades antioxidantes (SANTOS et al., 2017).

O maracujá amarelo (Passiflora edulis S.), da família Passifloraceae, é uma fruta tropical de origem incerta (NASCIMENTO et al., 2013). Segundo Santos (2013) e Moreno (2015), esta fruta, também conhecida como maracujá-azedo, é a espécie mais expressiva comercialmente dentre as passiflorascultivadas no Brasil, seu maior produtor mundial. Isso se dá por sua utilização ir além da culinária, já que este também é cultivado com finalidade medicinal, para extração de sustâncias químicas como a passiflorina e a maracujina, ambas com propriedades farmacêuticas (BRITTO, 2013). Além disso, conforme Nascimento et al. (2013), esta fruta é uma excelente fonte de vitamina do complexo B (B2, B5 e niacina) e de sais minerais (cálcio, potássio e fósforo).

O meloeiro (Cucumis melo L.) é uma olerícola da família Cucurbitácea, de clima tropical, com grande importância econômica e social, cultivada e apreciada em diversas regiões do globo (SILVA et al., 2018). Antunes et al. (2017) dizem que sua origem genética não está claramente estabelecida. Dalastra et al. (2016) declaram ser originária dos quentes vales do Irã e do noroeste da Índia; Valadares et al. (2017) defendem que seu centro de origem envolve as regiões tropicais e subtropicais da África; e Vieira et al.(2017) concordam com ambos, dizendo ser asiática e africana. Quanto aos aspectos nutricionais, a mesma possui elevados teores de carboidratos $(92,8 \mathrm{~g} .100 \mathrm{~g}-1)$, vitamina A $(116 \mathrm{mcg} .100 \mathrm{~g}-1)$ e vitamina C (29 mg.100g-1) (VIEIRA et al., 2017).

A pera 'Rocha' (Pyrus communis L.), da família Rosaceae, é uma cultivar de origem portuguesa (GOMES, 2015). Nela é possível encontrar Caroteno, $\alpha$-tocoferol, Tiamina, Riboflavina, Niacina, Vitamina A, Vitamina B6, Vitamina B12, Vitamina C, Folatos; e os minerais Cinza, Sódio $(\mathrm{Na})$, Potássio $(\mathrm{K})$, Cálcio $(\mathrm{Ca})$, Fósforo $(\mathrm{P})$, Magnésio $(\mathrm{Mg})$, Ferro (Fe) e Zinco (Zn) (PEREIRA, 2017).

Para a comercialização de qualquer fruto para consumo in natura, a apresentação e qualidade visual do fruto são fundamentais. Portanto é importante que o produtor preze pela aparência e qualidade do fruto, garantindo que ele não apresente manchas, sujeira, murchamento ou danos causados por patógenos e pragas. Para isso é preciso planejar todo o cultivo e época de colheita (SILVA, 2017).

Ainda segundo Silva (2017), a qualidade do fruto pode ser interferida a partir de diferentes aspectos do fruto, tais como: coloração, sabor, aroma, rendimento de polpa, dimensões, além de outras características que atendam a preferência do consumidor final. Já no caso das indústrias, elas preferem que os frutos apresentem maiores teores de sólidos solúveis e rendimento de suco, não se preocupando tanto com a aparência.

A fruticultura tem influência significativa para a economia e alguns frutos precisam passar por melhoramento genético para que haja o crescimento da produção em quantidade e qualidade, para assim atender as exigências dos consumidores e das indústrias de processamento. Partindo dessa premissa, este estudo teve como objetivo analisar os dados da 
Revista da Universidade Estadual de Alagoas/UNEAL e-ISSN 2318-454X, Ano 12, Vol. 12 (3), julho/outubro (2020).

biometria de frutos comercializados em feiras livres do Agreste Alagoano para auxiliar como parâmetro da aquisição da compra.

\section{Materiais e Métodos}

Local da pesquisa

A pesquisa foi realizada nas feiras livres do agreste alagoano uma região de transição ecológica com influência social e econômica por se tratar de uma zona geográfica densamente povoada. A pesquisa se constituiu na coleta de frutos para aferição de medidas em laboratório. E incluiu-se nesse estudo uma entrevista com 200 (duzentos) entrevistados (usuários da feira), através de um questionário semiestruturado, os quais foram convidados de forma voluntária a participar do estudo.

Este trabalho atende aos requisitos de uma pesquisa de campo, onde na visão de Piana (2009), trata-se de um tipo de pesquisa que foca em buscar a informação diretamente com a população pesquisada, e que exige do pesquisador um encontro mais direto. Desta maneira, o pesquisador precisa ir ao espaço onde o fenômeno acontece, ou aconteceu e coletar todas as informações disponíveis, e necessárias, a serem documentadas.

Procedimentos metodológicos

O delineamento experimental planejado foi o inteiramente casualizado, onde o pesquisador escolheu aleatoriamente as bancas de feiras e a coleta dos frutos. Os tratamentos foram a coleta de dez espécies de frutos e as repetições cinco feiras semanais no período de outubro de 2019 a fevereiro de 2020.

Os frutos foram estudados em triplicatas, utilizando-se uma amostra de dez unidades de cada espécie em cada feira visitada. Cada feira coletou-se três frutos das dez espécies comercializadas. As espécies de frutos foram: abacate, goiaba, laranja, limão, maçã, manga, mamão, maracujá, melão e pera.

Após coletados nas feiras os frutos foram encaminhados ao laboratório de ciências Biológicas do Campus I da Universidade Estadual de Alagoas (UNEAL), onde ocorreu a verificação das variáveis dos frutos quanto ao diâmetro equatorial (DE) e polar (DP), biomassa, e número de sementes por fruto. Para mensuração das variáveis dos frutos utilizouse paquímetro universal analógico da marca Amatools $(150 \mathrm{~mm} / 6$ "), com precisão de 0,05 mm e, para aferição dos pesos, balança semi-analítica.

Análise dos dados

Os dados resultantes da entrevista dos voluntários foram registrados em planilhas do Excel para a inserção dos gráficos. Os dados da coleta das variáveis dos frutos foram submetidos à análise de variância por comparação de médias múltiplas através das médias de Games-Howell a 5\% de probabilidade. Para essa análise quantitativa da ANOVA e análise de regressão, utilizou-se o programa estatístico AGROESTAT (MALDONADO, 2020). 
Revista da Universidade Estadual de Alagoas/UNEAL e-ISSN 2318-454X, Ano 12, Vol. 12 (3), julho/outubro (2020).

\section{Resultados e Discussões}

Os entrevistados responderam ao questionário semiestruturado com participação efetiva e colaborativa ao entrevistador (a). Os dados revelam que o tamanho foi a característica mais significativa para a decisão da compra da fruta comercializada. Nessa variável a fruta com tamanho maior dentro da sua característica é um fator de decisão no momento da compra. Esse resultado concorda com o encontrado por Silva C. (2018) onde ele defende que, dentre os aspectos sensoriais, o tamanho, a aparência e peso das frutas são fatores determinantes para a decisão de compra por parte dos compradores. A figura 1 mostra os dados do desvio padrão que é uma medida indicando a dispersão dos dados dentro de uma amostra com relação à média. Assim, quando se calculou o desvio padrão juntamente com a média dos diferentes frutos, obteve-se as informações para avaliar e diferenciar o comportamento dos usuários para a decisão da compra da fruta.

Figura 1. Características agregadas ao fruto no momento da compra em feiras livres.

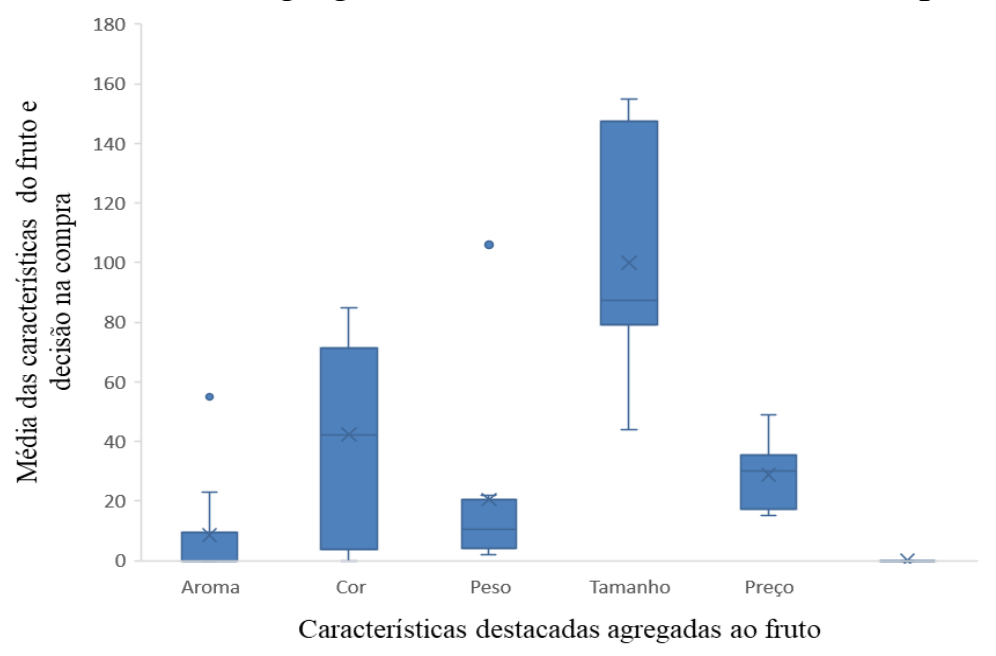

Fonte: Dados da pesquisa.

A figura 2 indica os dados em porcentagem da satisfação dos clientes em comprar o fruto por prazer no sabor da fruta. Os resultados revelam que o maracujá é a fruta cujo sabor tem destaque em meio à clientela. Talvez essa preferência pelo maracujá deva-se ao fato dele ser uma fruta que pode ser aproveitada em sua totalidade, pois além do seu uso para a produção de sucos e polpa, também há o aproveitamento da casca, a qual pode ser empregada no controle lipêmico (auxiliando na redução do colesterol), e na produção de farinha, a qual ajuda na flora intestinal e é consumida como suplemento dietético por pessoas portadoras de 
Revista da Universidade Estadual de Alagoas/UNEAL e-ISSN 2318-454X, Ano 12, Vol. 12 (3), julho/outubro (2020).

diabetes mellitus tipo 2, sendo útil no controle da glicemia. (CAZARIN et al., 2014; CHEOK, et al.,2016).

Figura 2. Satisfação na compra ligada ao sabor da fruta comercializada

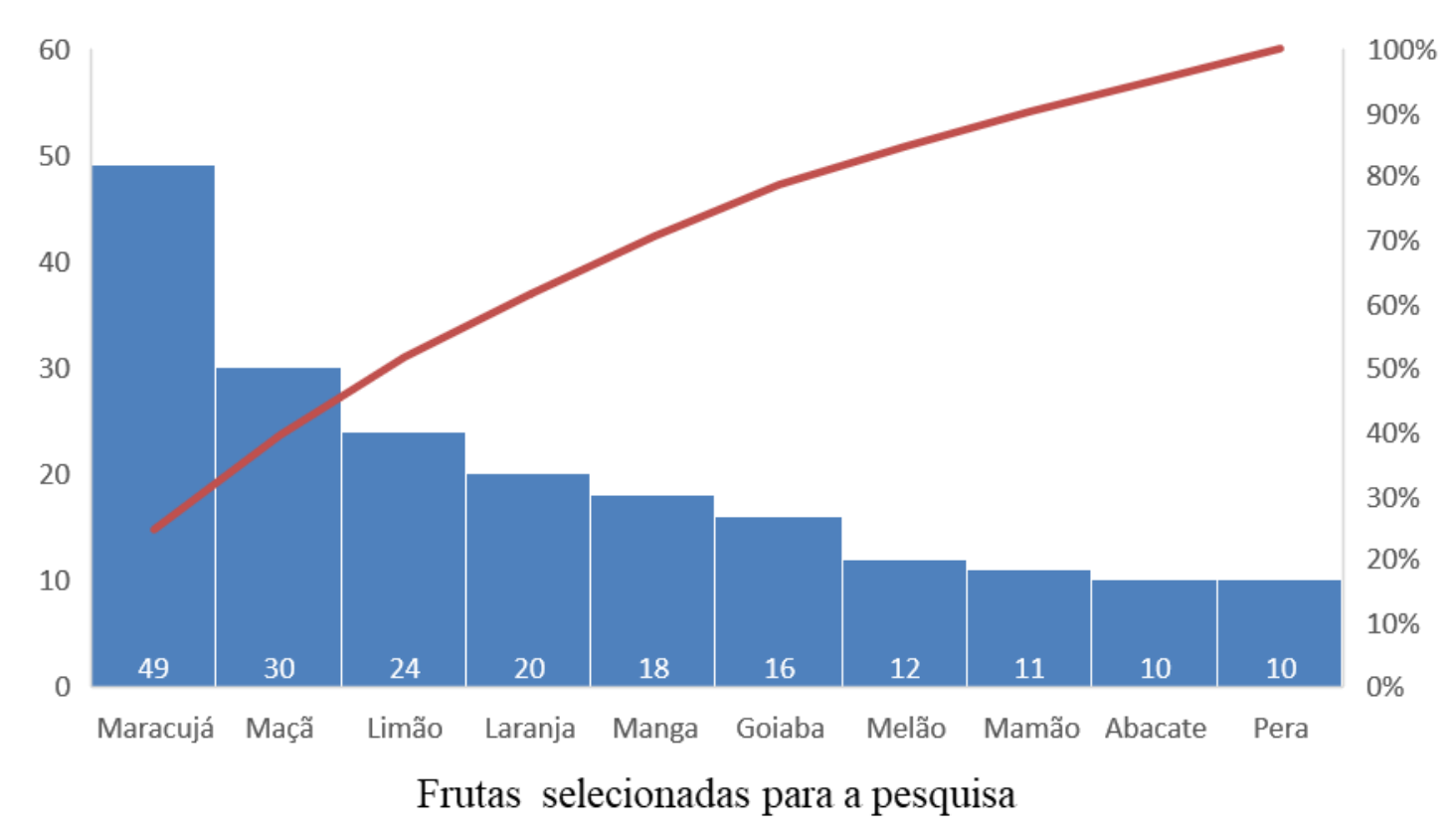

Fonte: Dados da pesquisa.

Foram coletados 3.450 (três mil e quatrocentos e cinquenta) frutos durante o período da pesquisa. Os dados coletados nas feiras livres revelaram diferença na biometria das dez espécies de frutos dessa pesquisa, nas variáveis morfológicas, e nas características de cada espécie comercializada. Como se vê (Figura 3) há diferenças entre os grupos de frutas que são específicas de cada família. Essas diferenças são objeto de estudo da Biometria, e esta por sua vez ajuda na caracterização das espécies, e na obtenção de informações para a exploração e conservação de recursos de valor econômico, servindo também como instrumento para detectar a variabilidade genética (GONÇALVES L. et al., 2013; SCHULZ et al., 2014).

Essas diferenças biométricas são encontradas nos frutos e nas sementes entre as espécies também em Hymenaea courbaril L. e Hymenaea stigonocarpa Mart. ex Hayne (ambas da família Fabaceae), assim a biometria se constitui numa ferramenta que poderá auxiliar na identificação das espécies em campo principalmente quando se tem duas matrizes próximas, onde os frutos e sementes são fenotipicamente semelhantes (BEZERRA et al., 2014). 
Revista da Universidade Estadual de Alagoas/UNEAL e-ISSN 2318-454X, Ano 12, Vol. 12 (3), julho/outubro (2020).

Figura 3. Dados brutos encontrados dos tratamentos analisados nas espécies de frutos da pesquisa.

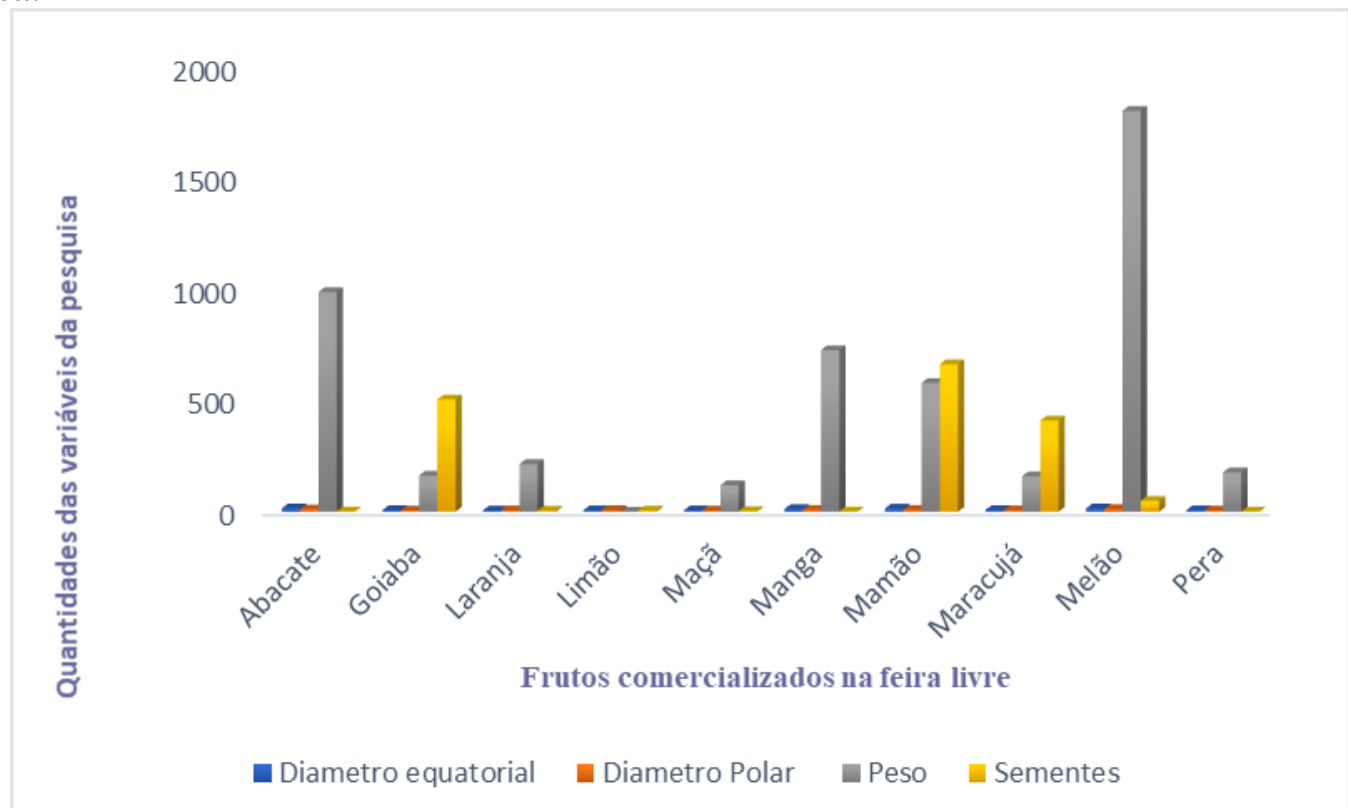

Fonte: Dados da pesquisa.

Nos dados analisados pelo cálculo estatístico, houve resultado significativo entre os tratamentos e nas coletas dos frutos nas feiras livres para o diâmetro equatorial dos frutos e do diâmetro polar dos frutos, bem como do peso do fruto e das sementes. Pelo teste $(\mathrm{F}=50.251)$ nas condições, $\mathrm{F}^{* *}(\mathrm{p} \leq 0,01)$ através da análise de variância, os dados foram significativos entre os tratamentos e as variáveis (Tabela 1).

Gonçalves et al. (2017) também encontraram resultados significativos ao estudar a biometria de frutos e sementes, porém estes focaram no fruto de Abieiro (Pouteria caimito). Trabalhando os valores médios da massa fresca, diâmetro e comprimento, encontraram valores inferiores aos de outros autores, e atribuíram essas diferenças às variações ambientais locais, como o manejo nutricional e o recurso hídrico, detalhes que podem favorecer as características físicas da espécie. Os resultados da presente análise biométrica não puderam ser comparados diretamente com outros autores, pois não foram encontradas pesquisas que já houvessem trabalhado a biometria de tantas espécies de uma única vez. Percebeu-se que, geralmente, na literatura os pesquisadores optam por trabalhar um fruto por vez, provavelmente isso se deva ao fato de terem um enfoque diferente. 
Revista da Universidade Estadual de Alagoas/UNEAL e-ISSN 2318-454X, Ano 12, Vol. 12 (3), julho/outubro (2020).

Tabela 1. Análise de variância para os efeitos principais e interações entre tratamento e variáveis.

\begin{tabular}{cccccc}
\hline $\begin{array}{c}\text { Causas de } \\
\text { variação }\end{array}$ & GL & SQ & QM & F & P \\
\hline Tratamento & 3 & 150,75 & 50,251 & $50,251^{* *}$ & $<0,0001$ \\
Resíduo & 34 & & & & \\
Total & 37 & & & & \\
Coeficiente de & & 39,48 & & \\
variação (\%) & & & & \\
\hline$* *$ significativo a 1\% de probabilidade respectivamente pelo teste F. (Fonte: Dados da pesquisa).
\end{tabular}

As médias de Games-Howell são usadas quando você não pressupõe igualdade de variâncias e não tem a testemunha entre os tratamentos. Sugere-se o seu uso quando os números de dados coletados das variáveis entre os grupos são diferentes e a variância também (MALDONADO, 2020). Nessa pesquisa a hipótese foi que a compra dos frutos é feita pela análise do tamanho (diâmetro equatorial - DE e diâmetro polar - DP), sendo DE referente à medida da "cintura" do fruto e a DP o comprimento do fruto (Tabela 2).

$\mathrm{O}$ resultado deste estudo é coerente com o dados encontrados por Neto Cerri et al. (2016), que, ao estudarem variedades de laranja, observaram que a variedade Sanguínea apresentou maiores valores para biomassa fresca, diâmetros polar e equatorial, e menor número de sementes, e perceberam que eram estas características que conferiam a ela maior valor comercial, pois se encaixam na preferência entre os consumidores.

Tabela 2. Médias múltiplas de Games-Howell dos tratamentos no experimento.

\begin{tabular}{cccc} 
Tratamentos & $\begin{array}{c}\text { Média (Games- } \\
\text { Howell) } \mathbf{p}<\mathbf{0 . 0 0 5}\end{array}$ & Desvio padrão & $\begin{array}{c}\text { Coeficiente de } \\
\text { variação }(\%)\end{array}$ \\
\hline Diâmetro equatorial dos frutos & $9,92 \mathrm{~b}$ & 3,94 & 39 \\
Diâmetro polar dos frutos & $8,11 \mathrm{~b}$ & 2,21 & 27 \\
Peso dos frutos & $547,57 \mathrm{a}$ & 334,54 & 39 \\
Sementes dos frutos & $109,00 \mathrm{a} \mathrm{b}$ & 56,3 & 38
\end{tabular}

Médias seguidas de mesma letra, em uma mesma coluna, não apresentam diferenças significantes, ao nível de significância de 5\% (Fonte: Dados da pesquisa).

Os dados se ajustaram ao modelo quadrático com os efeitos nos tratamentos, sendo o $\mathrm{R}^{2}=1,0$. Conforme se vê na Figura 4. Guimarães et al. (2020), ao analisarem a biometria dos frutos de cajarana (Spondias dulcis P.), perceberam que os valores de comprimento, diâmetro e peso avaliados na pesquisa deles diferiram (para mais e para menos) dos resultados obtidos 
Revista da Universidade Estadual de Alagoas/UNEAL e-ISSN 2318-454X, Ano 12, Vol. 12 (3), julho/outubro (2020).

por outros autores, mesmo tratando-se de apenas um fruto. Então, é normal que na presente análise biométrica os valores obtidos não sejam lineares e não coincidam com o resultado de outras pesquisas, por se tratar de frutos de espécies diferentes. Nesses dados observa-se um comportamento da curva das variáveis analisadas durante as coletas dos frutos como efeito principal dos tratamentos. Geralmente o tamanho e o peso das sementes em espécies de interesse comercial ou agrícola, podem ser considerados um indicativo de sua qualidade fisiológica, tanto na germinação ou no crescimento inicial das plantas, em decorrência da quantidade de reservas acumuladas e da formação do embrião (NETO S. et al., 2009).

Figura 4. Modelo quadrático de ajuste das medidas dos frutos coletados nas feiras livre.

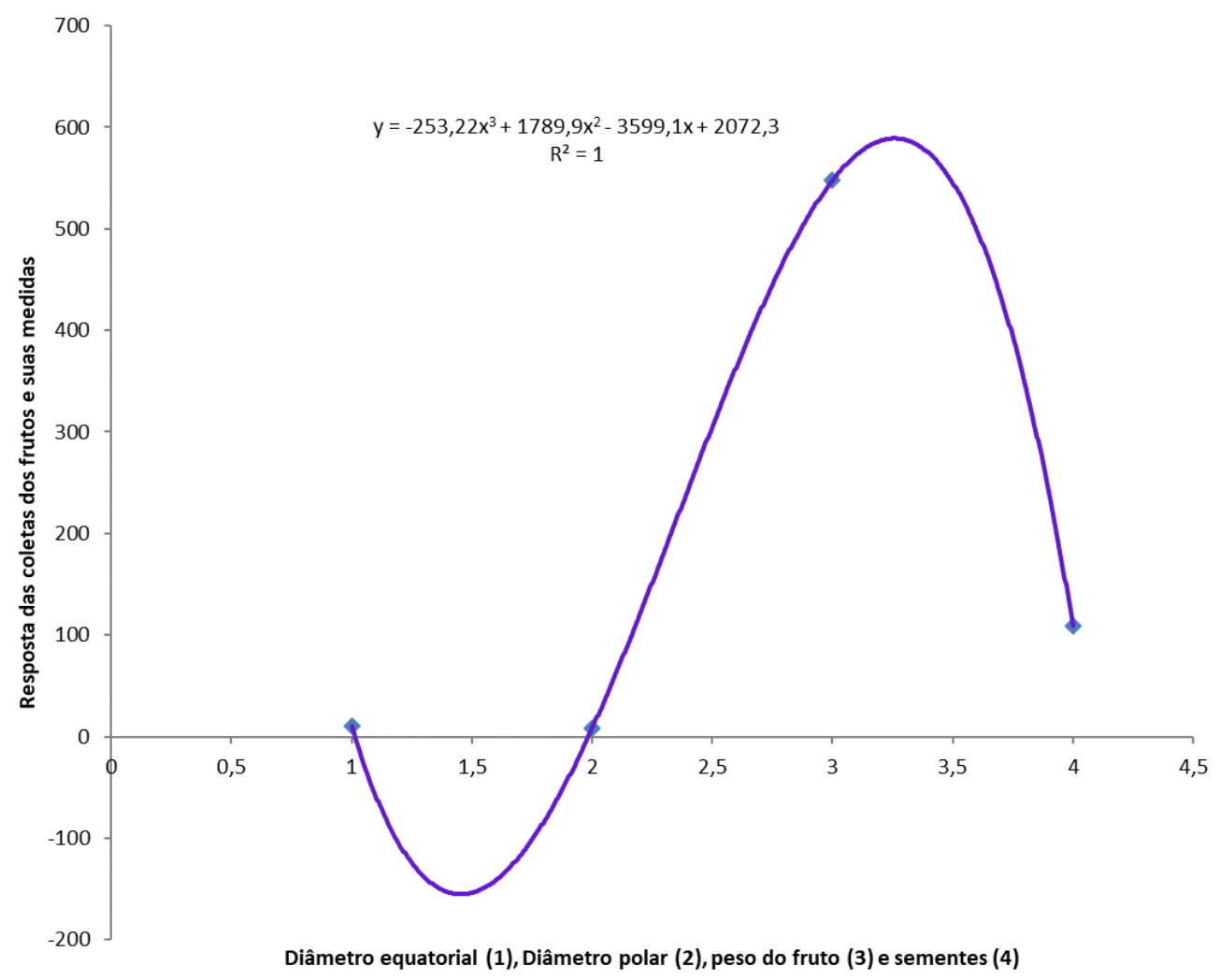

Fonte: Dados da pesquisa.

\section{Conclusão}

A pesquisa concluiu que dentre as variáveis analisadas em cada espécie, as de maior influência no momento da compra dos frutos foram tamanhos (diâmetro equatorial dos frutos e diâmetro polar) e massa. Este levantamento poderá ser uma útil ferramenta para trabalhos posteriores na área de melhoramento genético, onde se poderá buscar melhorar a qualidade 
Revista da Universidade Estadual de Alagoas/UNEAL e-ISSN 2318-454X, Ano 12, Vol. 12 (3), julho/outubro (2020).

das frutas, trabalhando principalmente as características de maior influência no momento da compra sem perder qualidade nos demais requisitos, objetivando aumento da produção, aumento das vendas e consequente elevação nos rendimentos financeiros relacionados à fruticultura.

\section{Agradecimentos}

Ao grupo de estudos ambientais e etnobiológicos - GEMBIO (Uneal - Campus I).

\section{Conflito de interesses}

Os autores deste manuscrito não declararam conflitos de interesse.

\section{Referências}

ANTUNES, A. M. et al. Cucumis melo L. minimamente processado e armazenado em diferentes embalagens. Revista Espacios, v. 38, n. 51, p. 1-9, 2017. Disponível em: <https://www.revistaespacios.com/a17v38n51/a17v38n51p01.pdf> Acesso em: 14 Jul 2020.

ARAÚJO, et. al. Caracterização Morfométrica e Germinação de Sementes de Macroptilium martii Benth. (FABACEAE). Revista Caatinga, Rio Grande do Norte, v. 27, n. 3, Jul./Set. 2014. Disponível em: <https://periodicos.ufersa.edu.br/index.php/caatinga/article/view/3641> Acesso em: 14 Jul 2020.

ARAÚJO, D. M. et. al. Aspectos de Aquisição e Consumo de Peixes na Feira Livre da Cidade de Penedo - Alagoas. Boletim do Instituto da Pesca, São Paulo, v. 41, n. 2, 2015.

Disponível em: < https://www.bvs-vet.org.br/vetindex/periodicos/boletim-do-instituto-depesca/41-(2015)-2/aspectos-de-aquisicao-e-consumo-de-peixes-na-feira-livre-da-cidade-de-/> Acesso em: 18 Abr 2020.

BASTOS, E. M. et. al. Características sociodemográficas dos permissionários de produtos da sociobiodiversidade em mercados públicos no nordeste brasileiro. Brazilian Journal of Development, Curitiba, v. 6, n.4, p.19553-19574. 2020. Disponível em: <http://www.brjd.com.br/index.php/BRJD/article/view/8791> Acesso em: 18 Abr 2020.

BEZERRA, F.T.C. et al. Biometria de frutos e sementes e tratamentos pré-germinativos em Cassia fistula L. (Fabaceae-Caesalpinioideae). Semina: Ciências Agrárias, v. 35, n. 4, p.2273- 2286, 2014. Disponível em: <. doi: 10.5433/1679-0359.2014v35n4Suplp2273>. Acesso em: 14 Ago 2020. 
Revista da Universidade Estadual de Alagoas/UNEAL e-ISSN 2318-454X, Ano 12, Vol. 12 (3), julho/outubro (2020).

BRITTO, F. F. Progênies híbridas de maracujazeiros do cruzamento Passiflora cincinnata Mast. x Passiflora quadrangularis Linn. Dissertação (Mestrado) - Programa de Pós-Graduação em Agronomia. Área de Concentração em Fitotecnia, Universidade Estadual do Sudoeste da Bahia, Vitória da Conquista, 2013. Disponível em:

$<\mathrm{http}$ //sucupira.capes.gov.br/sucupira/public/consultas/coleta/trabalhoConclusao/viewTrabal hoConclusao.jsf?popup=true\&id_trabalho=102075> Acesso em: 10 Out 2018.

CAZARIN, et. al. Capacidade antioxidante e composição química da casca de maracujá (Passiflora edulis). Ciência Rural, v. 44, n. 9, 2014. Disponível em:

<https://www.redalyc.org/html/331/33132415029/>. Acesso em: 30 Ago 2020.

CHEOK, et. al. Current trends of tropical fruit waste utilization. Critical reviews in food science and nutrition, v. 58, n. 3, p. 335-361, 2016. Disponível em:

<https://www.researchgate.net/profile/Choon_Yoong_Cheok/publication/303715694_Current _Trends_of_Tropical_Fruit_Waste_Utilization/links/59e56a930f7e9b0e1aa89254/CurrentTrends-of-Tropical-Fruit-Waste-Utilization.pdf>. Acesso em: 30 Ago 2020.

COELHO, E. M. et al. Prospecção Tecnológica para o aproveitamento de resíduos industriais, com foco na indústria de processamento de manga. Cadernos de Prospecção, v. 7, n. 4, p. 550, 2014. Disponível em: <https://portalseer.ufba.br/index.php/nit/article/view/11566>. Acesso em: 24 Abr 2020.

DALASTRA, G. M. et al. Produção e qualidade de três tipos de melão, variando o número de frutos por planta 1. Revista Ceres, v. 63, n. 4, p. 523-531, 2016. Disponível em:

$<$ http://www.scielo.br/scielo.php?script=sci_arttext\&pid=S0034-

737X2016000400523\&lng=pt\&tlng=pt>. Acesso em: 24 Abr 2020.

EMBRAPA. Mamão: o produtor pergunta, a Embrapa responde. 2013. Disponível em: <https://www.embrapa.br/mandioca-e-fruticultura/busca-de-publicacoes/-

/publicacao/979299/mamao-o-produtor-pergunta-a-embrapa-responde> Acesso em: 24 Abr 2020.

FACHINELLO, et. al. Situação e perspectivas da fruticultura de clima temperado no Brasil.

Revista Brasileira de Fruticultura, Jaboticabal, p.109-120, 2011. Volume Especial.

Disponível em: <https://wp.ufpel.edu.br/fruticultura/files/2011/10/pag109_120-Palestra097-

11.pdf> Acesso em: 30 Set 2019.

FERREIRA, T. H. B. et al. PROPRIEDADES FÍSICAS, QUÍMICAS E NUTRICIONAL DO NÉCTAR DE LARANJA INDUSTRIALIZADO. GLOBAL SCIENCE AND

TECHNOLOGY, v. 12, n. 2, p.60-67. 2019. Disponível em:

<https://rv.ifgoiano.edu.br/periodicos/index.php/gst/article/view/1111/663> Acesso em 15 de Ago 2020. 
Revista da Universidade Estadual de Alagoas/UNEAL e-ISSN 2318-454X, Ano 12, Vol. 12 (3), julho/outubro (2020).

GUIMARÃES, A. R. D. et al. Caracterização física e química de frutos da cajarana (Spondias dulcis Parkinson)/Physical and chemical characterization of cajarana fruits (Spondias dulcis Parkinson). Brazilian Journal of Development, v. 6, n. 2, p. 6693-6701, 2020. Disponível em: <https://www.brazilianjournals.com/index.php/BRJD/article/view/6795/5985>. Acesso em 25 de Set 2020.

GOMES, Gaspar Duarte. Acastanhamento interno durante o armazenamento da pera 'Rocha': Impacto do baixo O2 e alto O2 no metabolismo e estratégias de controlo. 2015. Dissertação (Mestrado de Engenharia Agronômica) - Faculdade de Ciências Universidade do Porto. Porto, Portugal.Disponível em: <https://repositorioaberto.up.pt/bitstream/10216/83416/2/127572.pdf>. Acesso em: 14 Jun 2020.

GONÇALVES, L. G. V.et. al.Biometria de frutos e sementes de mangaba (Hancornia speciosa Gomes) em vegetação natural na região leste de Mato Grosso, Brasil. Revista de Ciências Agrárias, Pernambuco, v. 36, n.1, p. 31-40, 2013. Disponível em: <http://www.scielo.mec.pt/scielo.php?script=sci_arttext\&pid=S0871-018X2013000100006> Acesso em: 14 Jun 2020.

GONÇALVES, B. H. L. et al. BIOMETRIA DOS FRUTOS E USO DE ÁCIDO GIBERÉLICO NA GERMINAÇÃO DE SEMENTES DE ABIEIRO (Pouteria caimito). Cultura Agronômica: Revista de Ciências Agronômicas, v. 26, n. 4, p. 530-539, 2017. Disponível em: <https://ojs.unesp.br/index.php/rculturaagronomica/article/view/24468355.2017v26n4p530-539/1835> Acesso em: 14 Jun 2020.

GUINÉ, Raquel. Projeto de uma Indústria de Processamento de Néctares de Maçã e de Pera. Millenium-Journal of Education, Technologies, and Health, n. 42, p. 175-189, 2016. MALDONADO Jr, W. AgroEstat Online. Disponível em: 〈http://www.agroestat.com.br〉. Acesso em: 13 Set 2020.

MELO FILHO, R. G. Aceitação Sensorial de Barras de Cereais Elaboradas com o Resíduo Agroindustrial da Goiaba. 2020. Monografia de Conclusão de Curso (Curso Superior de Tecnologia em Alimentos) - Instituto Federal de Educação, Ciência e Tecnologia Goiano -Morrinhos, Goiás. Disponível em:

<https://repositorio.ifgoiano.edu.br/handle/prefix/1119>. Acesso em 15 de Ago 2020.

MORENO, et. al. Biologia Floral, Morfometria e Viabilidade Polínica do Maracujá-Amarelo (Passiflora edulis Sims f. Flavicarpa Degener). Enciclopédia Biosfera, Goiânia, n.21, jun. 2015. Disponível em:

<http://www.conhecer.org.br/enciclop/2015b/biologicas/biologia\%20floral.pdf >. Acesso em: 16 Ago 2018.

NASCIMENTO, et. al. Benefícios e perigos do aproveitamento da casca de maracujá (Passiflora edulis) como ingrediente na produção de alimentos. Rev Inst Adolfo Lutz, v. 72, n. 1, p. 1-9, 2013. Disponível em: <http://www.ial.sp.gov.br/resources/insituto-adolfo- 
Revista da Universidade Estadual de Alagoas/UNEAL e-ISSN 2318-454X, Ano 12, Vol. 12 (3), julho/outubro (2020).

lutz/publicacoes/rial/10/rial72_1_completa/artigos-separados/rial1536.pdf >. Acesso em: 20 Ago 2018.

NETO, A. L. S.; et al. Influência do peso da semente e promotores químicos na qualidade fisiológica de sementes de sambacaitá. Revista Caatinga, Mossoró, v.22, n.1, p.187-192, 2009. Disponível em: <https://periodicos.ufersa.edu.br/index.php/caatinga/article/view/410>. Acesso em: 17 Set 2020.

NETO, C. B. et al. Caracterização físico-química das frutas de sete genótipos de laranjas da coleção de Citrus spp. Incaper, Fazenda Experimental de Sooretama, Espírito Santo. 2016. Disponível em: <https://biblioteca.incaper.es.gov.br/digital/handle/item/2522>. Acesso em: 17 Ago 2020.

NOGUEIRA-DE-ALMEIDA, C. A. et al. Perfil nutricional e benefícios do azeite de abacate (Persea americana): uma revisão integrativa. Brazilian Journal of Food Technology, v. 21, 2018. Disponível em: <https://www.scielo.br/scielo.php?pid=S198167232018000100308\&script=sci_arttext>. Acesso em: 17 Ago 2020.

OLIVEIRA, L. A. E.; MENELAU, S. Atributos do produto e influências ambientais no comportamento do consumidor de suco de laranja do Distrito Federal. Organizações Rurais \& Agroindustriais, v. 19, n. 1, 2017. Disponível em: <http://revista.dae.ufla.br/index.php/ora/article/view/1100>. Acesso em: 09 Mar 2020.

OLIVEIRA JÚNIOR, A. B. Elaboração de sorvete à base de melão cantouloupe (Cucumis melo var. cantalupensis) com adição de farinha de limão. 2019. Monografia de Conclusão de Curso(Engenharia de Alimentos)- Universidade Federal do Rio Grande do Norte. R Rio Grande do Norte. Disponível em: <https://monografias.ufrn.br/jspui/handle/123456789/8712>. Acesso em: 09 Ago 2020.

PATTARO, L. et al. Análises físico-químicas e sensoriais de smoothies do leite de diferentes espécies fermentado por kefir, saborizados com banana e maçã. Research, Society and Development, v. 9, n. 5, p. e112953145-e112953145, 2020. Disponível em: <https://www.rsdjournal.org/index.php/rsd/article/view/3145>. Acesso em: 30 Ago 2020.

PEREIRA, K. C. et al. Desenvolvimento de cultivares de goiabeira inoculadas com Meloidogyne enterolobii. Nematropica, v. 46, n. 1, p. 54-59, 2016. Disponível em: <http://jourNals.fcla.edu/nematropica/article/view/88205>. Acesso em: 11 Ago 2020.

PEREIRA, Cristiana Lucas. Monitorização da conservação de pera Rocha: avaliação de características de qualidade. 2017. Dissertação (Mestrado em Engenharia Alimentar Processamento de Alimentos) - Instituto Superior de Agronomia da Universidade de Lisboa, Lisboa, Portugal Disponível em: <https://www.repository.utl.pt/handle/10400.5/15118>. Acesso em: 11 Ago 2020. 
Revista da Universidade Estadual de Alagoas/UNEAL e-ISSN 2318-454X, Ano 12, Vol. 12 (3), julho/outubro (2020).

PIANA, Maria Cristina. A construção do perfil do assistente social no cenário educacional. 2009. Disponível em: 〈http://books.scielo.org/id/vwc8g>. Acesso em: 10 Ago 2020.

RODRIGUES, Roberto. Frutas para o mundo. Agro ANALYSIS, v. 35, n. 1, p. 45, 2015.

SANTOS, Anselmo Azevedo dos. Exploração de uma Biblioteca Genomica de Passiflora edulis f. flavicarpa por Sequenciamento de BAC-ends. 2013. Tese de Doutorado. Universidade de São Paulo. Disponível em: <http://www.teses.usp.br/teses/disponiveis/11/11137/tde-22082013-160154/pt-br.php >. Acesso em: 10 Ago 2020.

SANTOS, J. C. R. et al. DESENVOLVIMENTO DE BEBIDA MISTA A BASE DE AIPIM, MANGA E MEL. Anais Seminário de Iniciação Científica, n. 21, 2017. Disponível em: <http://periodicos.uefs.br/index.php/semic/article/view/2246/1703>. Acesso em: 09 Ago 2020.

SCHULZ, et. al. Maturidade Fisiológica e Morfometria de Sementes de Inga laurina (Sw.) Willd. Floresta e Ambiente, Paraná, 2014. Disponível em: <http://www.scielo.br/pdf/floram/2014nahead/aop_floram_054713.pdf >. Acesso em: 09 Ago 2020.

SILVA, et al. Panorama da fruticultura no Espírito Santo - Brasil. Revista Verde de Agroecologia e Desenvolvimento Sustentável, Rio grande do Norte, v. 8, n. 5, 2013. Disponível em: <https://www.gvaa.com.br/revista/index.php/RVADS/article/view/1949>. Acesso em: 09 Ago 2020.

SILVA, A. M. Qualidade pós-colheita de frutos de maracujá. Monografia de Conclusão de Curso (Graduação em Agronomia) - Faculdade de Agronomia e Medicina Veterinária da Universidade de Brasília, Brasília, Distrito Federal. 2017. Disponível em: <https://bdm.unb.br/handle/10483/20313>. Acesso em: 09 Ago 2020.

SILVA, S. C. Levantamento sobre perdas em frutas, legumes e hortaliças em feiraslivres no município de Londrina-PR. Monografia de Conclusão de Curso (Graduação em Tecnologia em Alimentos) - Universidade Tecnológica Federal do Paraná. Londrina, Paraná. 2018. Disponível em: <http://repositorio.roca.utfpr.edu.br/jspui/handle/1/10607>. Acesso em: 14 Set 2020.

SILVA, I. L. et al. Secagem e difusividade de sementes de melão. Revista de Ciências Agrárias, v. 41, n. 2, p. 21-30, 2018. Disponível em:

$<$ http://www.scielo.mec.pt/scielo.php?pid=S0871-

018X2018000200003\&script=sci_arttext\&tlng=es >. Acesso em: 14 Set 2020.

SOUZA, D. D.; CAVALCANTE, N. B. Biometria de frutos e sementes de Jatropha mollissima (Pohl) Baill. (Euphorbiaceae). Acta Biológica Catarinense, v. 6, n. 2, p. 115-122, 2019. Disponível em: <http://periodicos.univille.br/index.php/ABC/article/view/663>. Acesso em: 14 Set 2020. 
Revista da Universidade Estadual de Alagoas/UNEAL e-ISSN 2318-454X, Ano 12, Vol. 12 (3), julho/outubro (2020).

TEIXEIRA, M. A.; OLIVEIRA, R. A FEIRINHA DE ITAGUARA (MG): cores, aromas, sabores, ritmos e afetos. Ciências Gerenciais em foco. Minas Gerais, v. 8, n. 5, 2017. Disponível em: <http://revista.uemg.br/index.php/cgf/article/view/3353>. Acesso em: 04 Abr 2019.

VALADARES, R. N. et al. Estimativas de parâmetros genéticos e correlações em acessos de melão do grupo momordica. Horticultura Brasileira, v. 35, n. 4, p. 557-563, 2017.

Disponível em: <https://www.scielo.br/scielo.php?pid=S0102-

05362017000400557\&script=sci_arttext>. Acesso em: 04 Ago 2019.

VIEIRA, R. F. F. A. et al. Adição de farinha da casca de melão em cupcakes altera a composição físico-química e a aceitabilidade entre crianças. Conexão Ci, v. 12, n. 12, p. 2230, 2017. Disponível em:

<https://periodicos.uniformg.edu.br:21011/ojs/index.php/conexaociencia/article/view/611>. Acesso em: 04 Ago 2019. 